\title{
ACARI, CIDADE (MAIS) LIMPA
}

\section{L. M. GALVÃO'}

${ }^{1}$ Diretoria Acadêmica de Ciências, Geografia - Instituto Federal do Rio Grande do Norte luiza.galvao@ifrn.edu.br

Artigo submetido em outubro/2013 e aceito em outubro/2013

\section{RESUMO}

Este trabalho tem por objetivo realizar uma breve reflexão acerca da concepção empírica de Acari como a cidade mais limpa do Brasil, assim referenciada na década de 70 do século XX. Como introdução, desenvolvemos considerações iniciais sobre cidade, tendo como recurso metodológico os conhecimentos adquiridos com a disciplina Arquitetura e Cidade no Brasil. Dando sequência ao texto, refletimos conceitualmente sobre cidade, espaço balizador para compreensão de Acari - cidade mais limpa; território, para compreensão da cidade como construção histórica e o Ambiente, cujo propósito foi associar o tema do trabalho à sustentabilidade socioambiental. Utilizamos dois contextos: o primeiro de crise e divulgação do título cidade mais limpa. O segundo, dizendo respeito à legislação urbanística e códigos de postura elaborados nos períodos imperial e republicano, que ordenaram o território de Acari nos dois últimos séculos, marcando a tradição de asseio, limpeza e higiene urbanas.

PALAVRAS-CHAVE: Acari, Cidade mais limpa, Ambiente.

\section{ABSTRACT}

This paper aims to conduct a brief reflection on the empirical design of Acari as the cleanest city in Brazil, as referenced in the 70s of last century. As an introduction, we developed initial considerations on the city, having as a methodological resource the knowledge acquired through the subject-matter Arquitetura e Cidade no Brasil. As a follow up to the text, we reflected conceptually about the city, a parameter space to understand Acari - the cleanest city; territory, to understand the city as a historic creation, and the
Environment, whose purpose was to associate the theme of the work to the social and environmental sustainability. We have used two contexts: the first of crisis and dissemination of the cleanest city title. The second, relating to urban legislation and city codes established in the imperial and republican periods, which ruled the territory of Acari in the last two centuries, marking the tradition of urban neatness, cleanliness and hygiene

KEYWORDS: Acari, The cleanest city, Environment. 


\section{ACARI, CIDADE (MAIS) LIMPA}

\section{INTRODUÇÃO}

Cada cidade tem sua própria história e seu jeito de ser. A dinâmica histórica e os entrelaçamentos físico-culturais de cada uma são construídos na tessitura do seu espaço e lhe conferem identidade. Toda cidade se constitui no lugar do fenômeno humano, portanto do trabalho, das práticas e representações sociais.

O reconhecimento do lugar associado a valores culturais reflete o modo de pensar, de fazer, de sentir e de praticar a cidade. Em Acari-RN, a estreita relação com a sua paisagem se revela através das imagens e representações recriadas pelos que a visitam, bem como pelo trabalho e formas de relacionamento da população no cotidiano urbano. Descobrir a cidade, como objeto de estudo, lugar de vivência de muitos atores sociais, nos instiga, recorrentemente, a conhecê-la melhor.

Partindo-se dessas considerações iniciais, tem-se como objetivo neste trabalho, realizar uma breve reflexão acerca da concepção empírica de Acari como a cidade mais limpa do Brasil, assim referenciada na década de 70 do século XX. A escolha desse recorte temporal decorreu do fato de que, nessa década, a cidade de Acari, localizada nas terras semiáridas do Seridó Potiguar, com 10.898 habitantes (IBGE, 1970), foi apresentada ao país em horário nobre e, na ocasião, pela principal rede de televisão nacional, como a cidade mais limpa do país. Esse fato jornalístico criou o mito da cidade mais limpa como mais um atrativo a ser somado aos seus já consagrados: casario colonial; as belezas das serras graníticas, contornando seu espaço; o Açude Gargalheiras; a Igreja barroca do Rosário; a imponente Igreja Matriz de Nossa Senhora da Guia; o Museu do Sertanejo, antiga casa de Câmara e Cadeia; e as tradições culturais locais.

Para a realização dessa reflexão, utilizamos como principais fontes de investigação empírica documentos municipais e cartas enviadas à Administração Municipal, felicitando a cidade pela exemplar condição socioambiental que lhe é atribuída pela reportagem, e que a transformou em uma cidade símbolo de saúde urbana até os dias atuais.

Ademais, considera-se também, nesta reflexão, o contexto de crises, no qual Acari se inseria à época da divulgação do título de cidade mais limpa, concomitante à desaceleração econômica provocada pelo fechamento das indústrias de beneficiamento de algodão, situadas no território urbano. 


\section{BREVES REFLEXÕES: CIDADE, TERRITÓRIO E AMBIENTE}

Modernamente, a cidade é um lugar que registra crescimento e progresso. $E$ esses dois imperativos tornam-se, para a maioria dos moradores de uma cidade, orgulho e sentimento de que esse lugar vai se tornar desenvolvido. Entretanto, crescimento nem sempre é progresso e o progresso nem sempre é duradouro.

No Brasil, o crescimento das cidades posterior à 2a Guerra Mundial resultou do processo de industrialização, que redefiniu a expansão e plano físico das cidades, através do desenvolvimento do transporte rodoviário que, por sua vez, favoreceu o crescimento também das cidades do interior. Ou seja, a ligação dos centros e polos urbanos mais desenvolvidos com pequenas cidades, através dos sistemas de transportes, possibilitou também a urbanização no interior.

No contexto da industrialização - urbanização posterior aos anos 50, o município de Acari experimentou o progresso e esse fenômeno se deu através do desenvolvimento agroindustrial com a instalação de duas indústrias de beneficiamento de algodão; uma de capital regional, a Nóbrega \& Dantas S/A - Indústria e Comércio (Nóbrega \& Dantas), e a outra de capital inglês, do grupo Sociedade Algodoeira do Nordeste Brasileiro (SANBRA). Estas fábricas aqueceram a economia do município; determinando o aumento da produção, renda, emprego, comércio e serviços.

$\mathrm{Na}$ década de 1970, momento de reordenamento das atividades produtivas, de crescimento econômico e urbano no Brasil, as cidades médias e grandes receberam vultosos investimentos, enquanto as pequenas cidades foram deixadas de lado. Com isso, e em particular, as pequenas cidades do Nordeste semiárido, de tradição fabril, ficaram de fora das políticas reestruturantes determinadas pelo planejamento regional da Superintendência do Desenvolvimento do Nordeste (SUDENE).

No Sertão algodoeiro, encerrava-se um ciclo vital que produziu a vida política, econômica e social do campo e da cidade. Essa realidade se manifestou de duas formas no Nordeste: transformou áreas que interessavam ao capital em enclaves do capitalismo avançado, e as áreas tradicionais, em enclaves da pobreza (OLIVEIRA, 1993, p. 75-76). Nesse contexto, e em particular em Acari, o município teve suas fábricas fechadas e passou a conviver com o castigo da crise da economia algodoeira.

Essa crise foi fruto, também, do pensamento econômico predominante no século XX, cuja percepção de modernização considerava o meio mais importante do que o fim, e o nível da atividade mais relevante do que os objetivos para os quais ela se destinava. Nessa perspectiva sobre modernização no Brasil, Faoro (1992) dizia é um traço de linhas duplas: a linha do paradigma e o risco do país modernizável.

Portanto, o risco foi anunciado. As crises econômicas e implicações socioambientais, presentes agora, são consequências da modernização econômica predominante no país, a qual 
criou espaços extremamente injustos e desiguais, caracterizados pela insustentabilidade socioeconômica e ambiental.

Assim, o território da cidade de Acari, como parte da sua própria história, viveu, na década de 1970, a experiência da transformação e da permanência, quando teve seu papel alterado pela nova divisão social do trabalho e por novas práticas sociais, condição e manifestação reveladas pelo movimento da própria sociedade, em seus aspectos econômico, político e cultural.

O desaquecimento da economia acariense gerou sérias implicações socioambientais, mas também reação à crise, na medida em que as dificuldades econômicas no município foram amenizadas com a divulgação do aparentemente novo conceito de a cidade mais limpa do Brasil, como um marketing ambiental se sobrepondo à crise algodoeira. Isso também contribuiu na retomada da experiência solidária acumulada historicamente no território em tela.

No mundo presente, é importante a reflexão sobre sustentabilidade para pensarmos as soluções para a cidade: Acari, cidade mais limpa. Para dar efetividade ao título que a mesma carrega, devem ser considerados os contextos de crise e resistência, na inseparabilidade entre a materialidade historicamente construída, que inclui a natureza e o seu uso, a ação humana e a política, pois Ambiente e Território são complementares. Portanto, a análise do meio ambiente urbano, na década de 70, requer uma análise acurada do território, com a finalidade de compreender a complexidade sociedade-natureza e os aspectos problemáticos dessa relação (STEINBERG, 2006).

Para Santos, o território tem conteúdo, é dinâmico, de permanente movimento e é visto como algo que está em processo e onde se dá o exercício da vida. Nessa acepção, o território, e tudo o que está contido nele, é um observatório geográfico e uma fonte de conhecimentos. Santos afirma ainda que "a sociedade exerce permanentemente diálogo com o território usado, e que esse diálogo inclui as coisas naturais e artificiais, a herança social e a sociedade em seu movimento atual" (2000, p. 24-26).

Nessa perspectiva, refletimos o território numa perspectiva cultural, como espaço construído pelos grupos sociais através do tempo, à medida e à maneira de suas tradições, pensamentos, sonhos e necessidades. No misto de crise e criatividade, estão as formas distintas de vida urbana, as quais se relacionam, cooperam e competem entre si para a produção da cidade.

O aproveitamento dos recursos presentes em cada território deve respeitar as condições socioculturais de cada povo, assim como as formas específicas de relações sociais entre o homem e a natureza em cada região (ALTEVATER, 1995).

A cidade, como território construído historicamente pelas sociedades ali instaladas, expressa por meio das dimensões política, econômica e cultural uma configuração capaz de criar uma pluralidade de modos de vida. Ela é por excelência, lócus do coletivo, do intersubjetivo; é também lugar da memória, do passado e do presente, inscritos nos espaços construídos pela vida cotidiana (Abreu, 1998). 
Além de politicamente estruturado, o território da cidade também tem uma dimensão simbólica e identitária dos grupos que a constituem historicamente. Por isso, cada cidade tem sua singularidade e o seu jeito próprio de ser. Para Jodelet (2002), a cidade constitui uma interrelação direta entre espaço significante e espaço construído, o que a fundamenta como objeto idealizado e concreto por meio das construções, do mercado, da vida cotidiana e dos espaços de sociabilidade.

O Território também se define pelas relações sócio históricas de determinado espaço, pelas suas relações de poder e seus conflitos. Nele são criadas mediações espaciais que proporcionem efetivo poder para a reprodução de um grupo social. Esse território, no pensamento de Haesbaert (2004), se modifica histórica e geograficamente e, nele, o homem se territorializa numa espécie de área-abrigo, fonte de recursos, dominantemente local.

No estudo de um território, segundo Haesbaert (2004, p. 74) "é imprescindível [...] que contextualizemos historicamente o 'território' com o qual estamos trabalhando", já que os elementos-chave que compõem o espaço mudam ao longo do tempo. Logo, a produção territorial sempre tem um ponto de partida que nunca é ileso das ações do passado. "O processo territorial desenvolve-se no tempo, partindo sempre de uma forma precedente, de outro estado de natureza ou de outro tipo de território" (RAFFESTIN, 1993, p. 31).

Empiricamente, a ligação entre sentir e pensar a cidade como mais limpa e o título de "a cidade mais limpa" está, possivelmente, associado à cultura histórica do "belo e asseado urbano" desde 1835, quando a, ainda, Vila de Acari, em pleno Império, editou uma Lei de Postura (Lei № 7), determinando a obrigatoriedade de se limpar as frentes de suas casas nas quatro festas principais do ano, sob pena de multa, bem como estabelecendo a obrigatoriedade de se construir respeitando o alinhamento das edificações em todas as povoações da Vila do Acari.

Logo, a adoção do título A cidade mais limpa do Brasil pelos acarienses parece natural, pois a limpeza de suas edificações e a manutenção da limpeza pública foram sempre observadas por todos desde a mais tenra infância até os dias atuais. A divulgação, na década de 1970, do título de cidade mais limpa fez crescer o interesse em visitar Acari por parte de turistas de todos os lugares e despertou no acariense a consciência do seu próprio território nascida da relação cultural com o espaço urbano, a qual passou a ser manifestada como identidade, pelo marco cultural; como forma simbólica, pela importância de seu próprio espaço e como paisagem urbana e seus significados, pela identidade social e étnica (CORRÊA, 2007, p. 176-179). Nesse sentido, o título, apesar da subjetividade que carrega, reforça os laços entre a aparência física e os elementos humanos e culturais da cidade (JODELET, 2002, P. 35).

Assim, a cidade proclamada como mais limpa merece o apoio de cada habitante do lugar, de cada visitante amigo. É um trabalho educativo, que começa nos lares, continua nas escolas $e$ persiste pela vida afora (SANTA ROSA, 1973, p. 114).

\section{ACARI, CIDADE (MAIS) LIMPA}


Constam na Primeira Legislatura Provincial (1835/37), no período do Império, as primeiras determinações obrigatórias para limpeza das fachadas das casas nas povoações e alinhamento de suas ruas (Lei no 7 - Postura, já mencionada). No 1ํ Período Republicano (1899/1930), o Código de Postura para a Cidade do Acari tornou obrigatória a pintura, a cada dois anos, das fachadas dos prédios situados em ruas e travessas, até o dia 06 de agosto, dia que marca o início das comemorações religiosas da festa da Padroeira Nossa Senhora da Guia, sob pena de multa.

O Código de Postura era organizado em dois capítulos, sendo que o 10 Capítulo tratava do ordenamento urbanístico e arquitetônico e o 2으 tornava obrigatório o asseio e limpeza das ruas e praças da cidade:

\section{M P É R I O}

Lei no 7 - POSTURA

Art. № 8 - Em todo o cabeça de casal será obrigado a ter limpas as frentes de suas casas nas povoações, nas quatros festas principais de cada hum ano, sob pena de pagar por cada vez que faltar a limpeza, duzentos réis para as despesas da Câmara.

Art. № 13 - Em ninguém poderá construir casas nas povoações senão no alinhamento das outras, sob pena de pagar dez mil réis para as despesas da Câmara, e será demolida a casa a custa do proprietário.

Passo da Assembléia Legislativa Providêncial, 23 de março de 1935.

(AA) João Teotônio de Souza e Silva - Vice-presidente. Joaquim Xavier Garcia de Almeida - Primeiro Secretário. José Nicácio da Silva - Segundo Secretário.

Secretaria da Câmara Municipal da Vila do Acari, em 4 de março de 1935

(a) Miguel Pinheiro de Vasconcelos Secretário.

Com isso percebe-se uma preocupação dos dirigentes com melhoramentos urbanos programados e a gestão da cidade, o que propicia contextualizá-las com as mudanças estruturais motivadas pelo pensamento moderno do primeiro período republicano no Brasil. Foi um período de reformas estruturais, voltadas para dar maior significado à cidade, através da política de higienização, da melhoria da circulação e preocupação com a estética.

Santa Rosa (1974) registra como melhoramentos urbanos em Acari, no período acima caracterizado, construções novas dos prédios da Prefeitura, do mercado público e do cemitério. Comenta também sobre as construções de um centro cultural e uma nova lavanderia pública, essa última projetada para as águas servidas não provocarem poluição ao leito do rio. Acrescenta a preocupação arquitetônica com ventilação, iluminação natural e instalações sanitárias nos prédios públicos e nos ambientes voltados aos serviços médicos e dentários.

Verifica-se, assim, a influência do passado na constituição da cidade limpa, deixada como herança pelo documento do Império (Lei de Postura № 7/1835) e adotada pela cultura 
urbanística republicana nos códigos de posturas municipais de Acari em 1899, 1929, 1948 e, no ainda em vigor, de 1983.

A Lei № 7-Postura, de 04 de março de 1835, no seu artigo 8으, determinava

Art. № 8 - Em todo o cabeça do casal será obrigado a ter limpas as frentes de suas casas nas povoações, nas quatro festas principais de cada hum ano, sob pena de pagar por cada vez que faltar a limpeza, duzentos réis para as despesas da Câmara.

O Codigo de Posturas da Intendencia municipal da Cidade do Acary, Promulgado pela Lei N. 1 de 14 de março de 1899, no seu Capítulo II - Do acceio e limpeza publicas das ruas e praças da cidade: mantém o mesmo princípio de 1835

Art. 8o - Os proprietários, e na falta destes os inquilinos, procuradores, administradores de irmandades, fabriqueiros, thesoureiros, etc. são obrigados a conservarem caiadas as frentes de seus prédios, quando estes forem em ruas e travessas, devendo de dois em dois anos renovar este serviço até o dia 6 de agosto sob pena de $10 \$ 000$ de multa.

Em 1929, O Regulamento Geral dos Serviços da Prefeitura de Acary, editado em 15 de março de 1929, no Capítulo V - Asseio e conservação dos logradouros, define no art. 116 que a Prefeitura é responsável pela limpeza quinzenal das praças, ruas e travessas da cidade e povoações do município. O artigo 117, por sua vez, explicita proibições de, entre outras, arremessar para a rua, agua servida, palhas, cascas, bagaços de frutas entre outras ações que prejudicassem o asseio e limpeza. O artigo 119 retoma a limpeza das edificações da área urbana sob pena de multa. Ressalte-se que, nesse instrumento legal, não há o prazo de dois anos, mas logo que estejam sujos:

Art. 119 - Os proprietários da área urbana são obrigados, sob pena de $10 \$ 000$ de multa:

1) a trazer seus prédios sempre limpos renovando a caiação e pintura, logo que estejam sujos.

No Código Municipal de Posturas - Lei no 51, de 23 de novembro de 1948, artigo 27, a Prefeitura define a obrigação de o município decretar a limpeza externa da edificação:

Art. 27 - A Prefeitura decretará a limpesa externa geral dos prédios encravados na zona urbana da cidade e vilas do municipio, a qual será obrigatória de dois em dois anos. Pena-multa de vinte a cem cruzeiros.

$\S$ Único - A limpesa geral de que trata este artigo consistirá em caiação e pintura geral das frentes, muros e oitões, (que deem para praças, ruas ou logradouros publicos), portas e janelas dos prédios, inclusive os reparos gerais das calçadas ou passeios publicos. 
O Capítulo VI - Da Higiene e Saúde Pública, dessa mesma Lei, define obrigações para a Prefeitura e proprietários ou inquilinos de manterem limpas e em bom estado os logradouros públicos e edificações.

Art. 29 - As ruas, praças e jardins, travessas, bêcos e logradouros públicos, nas zonas urbana e suburbana da cidade e vilas do município, serão conservadas pela Prefeitura completamente limpas e asseadas.

Art. 30 - O ocupante ou inquilino de qualquer predio, é obrigado a conservá-lo em bom estado de asseio e higiene, sendo-lhe vedado atirar para as ruas ou qualquer via publica, lixo, aguas servidas, animais mórtos, cisco ou qualquer entulho que possa prejudicar o aspecto e limpesa das ruas.

O Código de Posturas do Município de Acari, ora vigente, Lei № 506/83, de 31 de dezembro de 1983, no Capítulo III - Da higiene das habitações particulares e coletivas, estabelece no art. 54 que o morador é responsável perante as autoridades fiscais pela manutenção da habitação em perfeitas condições de higiene. 0 art. 57, por sua vez, reitera a obrigação determinada na legislação do período do Império:

Art. 57 - As residências e estabelecimentos, na cidade na zona urbana, deverão ser caiados e pintados de 2 (dois) em 2 (dois) anos, no mínimo, salvo exigência especiais das autoridades competentes.

Parágrafo Único - Mesmo sem decorrer o prazo estabelecido neste artigo, as residências e os estabelecimentos que apresentarem mal aspecto deverão ser caiados ou pintados, a juízo da autoridade competente.

Como se vê, a essência da limpeza e salubridade de Acari transformou-se em orgulho local e tem sido adotada na legislação urbanística e mantida por seus nativos e habitantes e por todos que a visitam. A cidade mais limpa, apesar de sua adoção tácita por todos, hoje já não é mais tão proclamada pelas administrações, podendo em um momento futuro levar a uma mudança de comportamento e esquecimento de uma tradição positiva pelas novas gerações.

\section{CONSIDERAÇÕES FINAIS}

Nos caminhos do espaço urbano acariense, edificou-se uma cidade constituída de objetos materiais e subjetividades produzidas desde a sua instalação como Vila. Os objetos materiais, preservados na paisagem e as subjetividades preservadas pela memória, têm origem no passado imperial, ocasião em que foi estabelecido o primeiro Código de Postura que ressaltou o aspecto da limpeza, asseio e higiene, conduzido até hoje como símbolo de salubridade para sua sociedade.

Um dos reflexos da concepção de ambiente urbano saudável está na conservação do patrimônio arquitetônico construído no centro da urbe, bem como na consciência dos habitantes, que se esforçam para manter a cidade limpa. A sustentabilidade ambiental tão 
discutida no mundo atual é experimentada na cidade em seu cotidiano, através das práticas socioambientais, que vão desde o ato de não jogar lixo em espaços públicos até a tradição anual de limpar as fachadas dos prédios públicos e privados nos meses de julho e agosto, quando da preparação da comunidade acariense para a sua maior festa religiosa e momento de encontros e memórias dos que não mais residem no município.

Pela sua tradição histórica, Acari se configura como território que resulta da soma e da síntese, sempre refeita da paisagem urbana produzida histórica e cotidianamente (SANTOS, 1996, p.73). Nessa perspectiva, ainda que breve, a reflexão aqui desenvolvida confirma a importância da herança cultural para a permanência da identidade de "cidade mais limpa". A adoção espontânea deste título pela sociedade acariense prescinde da obrigatoriedade legal, amplamente estabelecida em leis e códigos, e desenvolve na juventude um comportamento ambiental ecologicamente correto, gerando a expectativa de que o comportamento tradicional se perpetue na Cidade de Acari.

\section{REFERÊNCIAS}

1. ABREU, Maurício de Almeida. Sobre a memória das cidades. Revista da faculdade de Letras Geografia, I série, vol. XIV, Porto, 1998, PP. 77-97.

2. ALTEVATER, E. O preço da riqueza: pilhagem ambiental e a nona (des)ordem mundial. São Paulo: UNESP, 1995.

3. ESTUDOS AVANÇADOS, Print version ISSN 0103-4014. Estud. av.vol.6no.14 São Paulo, Jan./Apr.1992 disponível em http://dx.doi.org/10.1590/S0103-40141992000100002.

4. IBGE: Síntese de Indicadores Sociais Uma Análise das Condições de Vida da População Brasileira 2010, Estudos e pesquisas ISBN 978-85-240-4143-3

5. HAESBAERT, Rogério. O mito da desterritorialização: do "fim dos territórios" à multiterritorialidade. Rio de Janeiro: Bertrand Brasil, 2004, p.344

6. OLIVEIRA, Francisco de. Elegia para uma re(li)gião: SUDENE, Nordeste, Planejamento e Conflitos de Classes. 6. ed. Rio de Janeiro: Paz e Terra, 1993. 132 p.

7. RAFFESTIN, Claude. Por uma geografia do poder. São Paulo, Ática, 1993

8. SANTOS, Milton. Metamorfoses do espaço habitado. 4a edição. São Paulo, HUCITEC, 1996. $126 \mathrm{p}$

9. SOUZA, M. J. L. de. O território; sobre espaço e poder, autonomia e desenvolvimento. CASTRO, I. E. de; GOMES, P.C. da C. e CORRÊA. R. L. (Orgs). Geografia Conceitos e Temas. Rio de Janeiro: Bertrand Brasil, 1995

10. STEINBERGER, M. (Org.). Território, ambiente e políticas públicas espaciais. 1a. ed. Brasília: Paralelo 15 e LGE, 2006. v. 1. 406 p 